Thorax (1964), 19, 176

\title{
Congenital partial left pericardial defect with a bronchogenic cyst
}

\author{
SA N IP M UKERJEE \\ From New Delhi
}

Congenital deficiency of the pericardium is a rare anomaly which is not mentioned in standard surgical textbooks. Rarer still is the association of this defect with a bronchogenic cyst. I have found only three references to it in the literature ; one by Rusby and Sellors (1945), the second by Hamilton (1961), and the third one was a sequestrated lung cyst in a patient reported by Warner, Britt, and Riley (1958). The rarity of this condition will be appreciated by the observation that only 107 cases of congenital pericardial deficiency have been reported in the world literature during the course of the last 403 years ; and one solitary case of pericardial deficiency has been encountered in over 14,000 necropsies performed at the Johns Hopkins Hospital (Southworth and Stevenson, 1938).

In most instances the anomaly has been discovered at necropsy; only on 15 previous occasions has the absence of the pericardium been discovered or confirmed during operation. Even then it has usually been a chance finding except on three occasions when it was diagnosed before operation and thoracotomy was done to confirm two of these cases (Ellis, Leeds, and Himmelstein, 1959 ; Hering, Wilson, and Ball, 1960 ; Hamilton, 1961).

The purpose of this paper is to present the one hundred and eighth case of congenital pericardial deficiency and the sixteenth detected during operation. This case is the third associated with a congenital malformation of the lung, namely a bronchogenic cyst.

The cases of bronchogenic cyst reported since 1899 number 105, published mostly in the nonEnglish literature.

\section{CASE REPORT}

A 24-year-old married woman was admitted to the Willingdon Hospital, New Delhi, on 22 November 1961 with a history of having pain in the left side of the chest, which radiated to the left hypochondrium, and low-grade fever with cough for three years. She had noticed undue breathlessness six months before admission.

The past and family histories were of no significance, and no abnormality was detected on clinical examination except for some diminution of vocal fremities and resonance over the upper part of the left chest.

Radiographs of the chest showed an abnormal cardiac silhouette. The pulmonary artery appeared rather prominent, and a bilocular mass was visible protruding from the left upper mediastinum.

Fluoroscopy showed the mediastinal mass to be pulsatile; the pulsations were transmitted and distinct from the aortic pulsations. The pulmonary conus was pulsating more than usual but there was no pulmonary plethora or cardiac enlargement.

The electrocardiogram and all other relevant investigations were within normal limits. Her symptoms were thought to be related to the upper mediastinal mass, and a pre-operative diagnosis of a mediastinal tumour was made.

A left thoracotomy was performed through the bed of the fourth rib. A glistening bilocular cyst, adherent to the left upper lobe by multiple adhesions and with a pedicle running to the tracheo-bronchial region passing between the left pulmonary artery and the arch of the aorta, was seen. No communication between the cyst and the tracheo-bronchial tree could be detected. The pericardium was absent from the atrioventricular groove upwards, and the left atrial $\frac{D}{0}$ appendage was jumping in and out freely through the defect with each ventricular contraction. The root $N$ of the aorta, the pulmonary artery, and its left branch 0 were bare and in contact with the left lung. The $N$ defect had no posterior or superior margins; anteriorly the left phrenic nerve, and inferiorly a thin free edge curving round the left atrioventricular groove, formed its boundaries.

The parietal pleura was also deficient over the root of the lung anteriorly, exposing the hilar structures.

A finger passed inside the pericardium through the defect failed to detect any deficiency of the right pericardium.

The left lung was normal in appearance. The cyst was excised.

The patient was certain the next morning that the pain she used to get had disappeared. Recovery was 8 
uneventful and she has remained completely symptomfree since.

The post-operative radiographs showed that the prominence of the pulmonary conus persisted and the significance of this finding will be explained.

The histological report on the specimen stated: 'The cyst wall is lined by mucous-secreting columnar epithelium and, in places, stratified, ciliated epithelium. The subepithelial tissues show numerous mucoussecreting glands, cartilage, plain muscle, and blood vessels; all sections show similar appearances. Diagnosis: A bronchogenic cyst.'

\section{DISCUSSION}

Congenital deficiency of the pericardium is seldom diagnosed in life but, as Hering et al. pointed out, with more and more thoracotomies being performed these days and with better radiological facilities available, more cases are being detected during life.

Columbus in 1559 first reported this condition; he was followed by Vittre' in 1712 and Vienssens in 1715 (Otto, 1831). Some doubt exists as to whether these earlier reports were of cases of diffuse adhesive pericarditis or of genuine pericardial defects (Rusby and Sellors, 1945).

Ladd (1936) reported the first case of congenital pericardial deficiency detected during operation when he saw a bare heart from a laparotomy wound while repairing a diaphragmatic hernia. Subsequently other reports of the discovery of this anomaly at operation followed (Table I).

INCIDENCE Bor and Kafka (1961) put the incidence at $0.7 \%$ of surgical thoracic cases.

AETIOlogy Pericardial deficiency is said to result from incomplete development of one or both pleuro-pericardial folds, which are raised by the right and the left common cardinal veins or the ducts of Cuvier. The function of these folds is to shut off the pericardial cavity from the rest of the coelomic cavity. As the left duct of Cuvier atrophies earlier, a premature atrophy of the left duct of Cuvier will lead to a left-sided pericardial defect. This explains the preponderance of leftsided defects, as shown by Ellis and others (Ellis et al., 1959 ; Perna, 1909).

Defective formation of the septum transversum leads to a deficiency of the diaphragmatic portion of the pericardium; this has been adequately proved by Ladd's case, where such a defect was associated with a Bochdalek type of diaphragmatic hernia. An attempt has been made by Rusby and Sellors to explain the presence of a bronchogenic cyst or other lung abnormalities in association with
T A B LE I

15 CASES OF CONGENITAL PERICARDIAL DEFICIENCY SEEN AT OPERATION

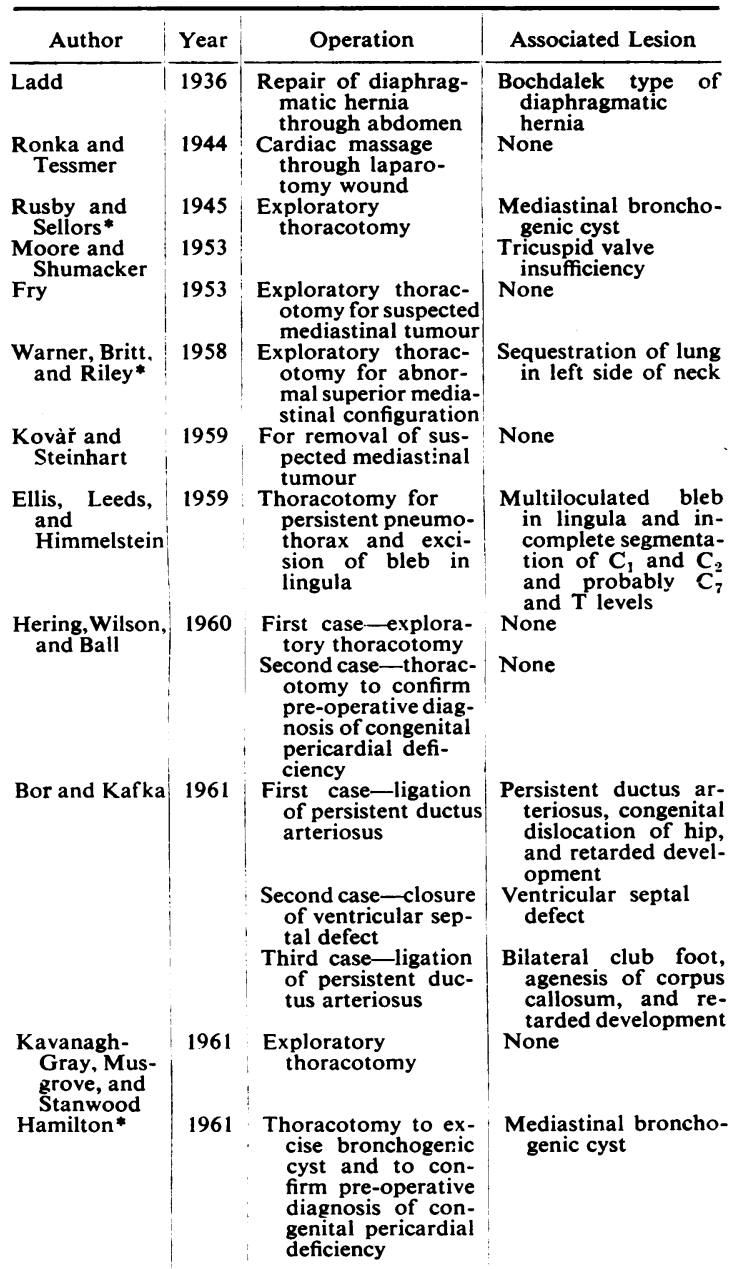

* These are the only three cases where a bronchogenic cyst was an associated feature.

a congenital pericardial deficiency. They postulated that, as the growing lung bud and the common cardinal vein are in close relation to each other, early atrophy of the common cardinal vein might enable the lung apex to push its way to the medial side of the duct, and, if this migrating part of the lung stops growing, a cyst containing bronchial elements can develop.

PATHology Fanfani and De Biase (1954) classified these defects into small or partial and large or complete. Ellis et al. (1959) collected 99 cases of pericardial defect and analysed them 
TABLE II

CLASSIFICATION OF PERICARDIAL DEFECTS SEEN TO DATE

(After Fanfani and De Biase, 1954)

A. Deficiency in development of pleuro-pericardium (pericardium and adjacent pleura)

1. Left side

(a) Foramen-type defects or partial defects $\quad \ldots \quad 25$

(b) Large or complete defects with common pericardial and left pleural cavity (commoner) ...

2. Right side

(a) Foramen-type defect

(b) Complete defect

3. Both sides (including foramen-type and complete

B. Incomplete formation of pericardium ${ }^{2}$ with ${ }^{\circ}$ normal formation of overlying parietal pleura with normaticar

C. Defects in diaphragmatic portion of pericardium (trans-

D. Unclassified (insufficient data)

according to this classification. They had to discard 14 out of the total cases as the available data were insufficient; to these I have added eight cases collected from the subsequent literature. The case presented here has also been added (Table II).

Many anomalies associated with pericardial deficiency have been noted (Table III). A broncho-

\section{TABLE III}

LESIONS ASSOCIATED WITH CONGENITAL PERICARDIAL
DEFICIENCY
Beart
Bifid apex of heart
Bicuspid aortic valve
Pricuspid valve disease
Versistent ductus arteriosus
Lung and pleura
Absence of fissures in left lung
Unusual lobulations of lung
Deficiency of overlying parietal pleura
Bronchogenic cyst
Diaphragm
Diaphragmatic hernia
Gut
Enterogenous cyst
Peritoneal cavity
Agenesis of left kidney
Brain
Agenesis of corpus callosum
Osseous system
Bilateral club foot
Congenital dislocation of hip
Incomplete segmentation of cervical spine

genic cyst, however, was discovered on only three previous occasions in association with this anomaly.

CLINICAL FEATURes The anomaly is seen predominantly in men; the ratio is three men to one woman.

The condition is usually asymptomatic.

Pain in the chest and mild dyspnoea have been described in some cases.

A cardiac murmur has also been heard in several patients. The cause of the cardiac murmurs found in some cases is not known, but a suggestion has been made that it is probably due to a turbulence resulting from repeated 'mechanical deformations' at the base of an excessively mobile heart (Ellis et al., 1959).

The pain has been attributed to the excessive tension on the anchoring structures at the base of the heart due to the deficiency of the supporting pericardium and also to the pull on the adhesions $\vec{x}$ between the heart and the visceral pleura which $\overrightarrow{0}$ are commonly seen in this condition (Ellis et al.). iv In one of their cases the intensity of the pain $\vec{v}$ varied with posture. One patient of Hering et al. $\sigma$ (1960) had excruciating chest pain, and the rolled 오 inferior margins of the defect were found to be rubbing on the left coronary and circumflex vessels with each contraction of the heart.

COMPLICATIONS This abnormality is generally of $\overrightarrow{\mathscr{O}}$ no consequence, but it can be dangerous.

Three fatal cases have been reported to date when herniation and strangulation of the heart took place through a moderate-sized partial pericardial defect (Boxall, 1887 ; Sunderland and Wright-Smith, 1944 ; Bruning, 1962).

Bor and Kafka (1961) in a recent paper have $\overrightarrow{\vec{P}}$ summarized the possible complications of this $\frac{3}{3}$ abnormality, which are as follows: (1) herniation of the heart, in large defects ; (2) interference with: the treatment of pulmonary tuberculosis by artificial pneumothorax ; (3) extension of infection $\underline{0}$ into the pericardium following infection of the $\underset{x}{\stackrel{0}{\nu}}$ lung or pleura ;4) technical difficulty of a surgeon $\dot{\sigma}$ while examining or operating on the thoracic contents (the authors experienced considerable difficulty in dissecting out a persistent ductus arteriosus in one of their patients due to theo prominent pulmonary artery arch and the left $\triangle$ atrium) ; and (5) following injury of the heart no을 symptoms of tamponade will be produced and thus delay in surgical intervention will result. There o will be no indication of a cardiac injury and it 0 will be impossible to treat a cardiac rupture N conservatively with repeated paracentesis, as 0 advocated by Wilkinson, Buttram, Reid, and Howard (1958).

DIAGNOSIS As has been pointed out recently by several authors (Ellis et al., 1959 ; Hering et al.,oำ 1960 ; Hamilton, 1961), a pre-operative diagnosis is possible using radiological methods if the $\stackrel{\mathbb{Q}}{\Omega}$ existence of this condition is borne in mind (Ellis et al., 1959 ; Hering et al., 1960 ; Hamilton, 1961). 
A lack of knowledge of the very existence of this anomaly is the reason why only four cases have been diagnosed by radiological methods to date (Dahl, 1937 ; Ellis et al., 1959 ; Hering et al., 1960 ; Hamilton, 1961). Again, in two out of these four cases the authors were wiser because in their first cases the abnormality had been a chance finding at operation.

A plain radiograph of the chest will show an abnormal cardiac contour due to the air-filled lung outlining the bare adjacent aorta, pulmonary artery, and the left atrial appendage. Also there will be a shift of the heart to the left without any displacement of the trachea (Ellis et al., 1959).

In the case presented here, the diagnosis was missed pre-operatively, but, in retrospect, one can see all these characteristics in the plain radiographs of the chest of this patient.

There are two confirmatory radiological methods available. (a) Selective angiocardiography, showing the pulmonary artery segment, the left atrial appendage and the aortic arch, can clinch the diagnosis, though Ellis et al. feel that, apart from excluding other abnormalities of the heart and making the abnormal cardiac contour more prominent, angiocardiography has not much to commend it. (b) Induction of artificial pneumothorax will produce a pneumopericardium in this condition and this is recommended by Ellis et al. But one must bear in mind that, apart from the risk of infection of the pleural cavity, the usual bugbear of this method, a sudden bilateral pneumothorax may result if there is bilateral deficiency of the pericardium.

If associated cardiac anomalies are present then, in spite of all these methods, the condition will still elude the clinician.

TREATMENT Since the condition is usually asymptomatic it does not require treatment.

The indications for treatment are the presence of symptoms or uncertainty regarding the diagnosis.

Hering et al. have put forward the following methods of treatment and these should be applicable to partial defects only: (1) atrial appendicectomy to prevent herniation of the left atrial appendage ; (2) division of adhesions which are regarded as the cause of pain ; and (3) pericardioplasty. Out of the 15 operated cases of pericardial deficiency a partial repair of the defect was attempted on only one occasion (Kavanagh-Gray, Musgrove, and Stanwood, 1961). A V-shaped excision of the inferior edge of the defect was performed in one patient as the edge was pressing against the coronary vessels (Hering et al., 1960).
SUMMARY

A case of congenital deficiency of the pericardium associated with an abnormality of the lung, namely a bronchogenic cyst, is presented. The association of such a cyst with a pericardial defect has been seen on only three previous occasions. In two of them the cyst was present in the mediastinum.

This is also the one hundred and eighth case of congenital deficiency of the pericardium reported to date and the sixteenth case of this anomaly detected at operation.

The aetiology, pathology, clinical features, and treatment are discussed and the need for a preoperative diagnosis is stressed.

The literature is reviewed.

I would like to thank Mr. L. R. Pathak, F.R.C.S.Ed., Professor of Clinical Surgery, Lady Hardinge Medical College, New Delhi, and Dr. H. L. Khosla, Medical Superintendent, Willingdon Hospital, New Delhi, for allowing me to publish this paper. My thanks are also due to Dr. G. S. Sarin for the radiological investigations and to Dr. H. P. Verma, senior anaesthetist, Willingdon Hospital.

\section{REFERENCES}

Bor, I., and Kafka, V. (1961). Aplasia of the pericardium. J. cardicvasc. Surg., 2, 389.

Boxall, $\mathbf{R}$. (1887). Incomplete pericardial sac; escape of heart into left pleural cavity. Trans. obstet. Soc. Lond., 28, 209.

Bruning, E. G. H. (1962). Congenital defect of the pericardium. $J$. clin. Path., 15, 133.

Columbus, M. R. (1559). De re Anatomica, Book 15, p. 265. Beuilacquae, Venice.

Dahl, E. (1937). Case of congenital defect of pericardium revealed after application of sinistrolateral pneumothorax. Med. Rev. (Bergen), 54, 312.

Ellis, K., Leeds, N. E., and Himmelstein, A. (1959). Congenital deficiencies in the parietal pericardium. Amer. J. Roentgerol., 82, 125.

Fanfani, M., and De Biase, G. (1954). Le agenesie del pericardio. Arch. De Vecchi Anat. pat.. 22, 1003.

Fry, W. (1953). Herniation of the left auricle. Amer. J. Surg., 86, 736.

Hamilton, L. C. (1961). Congenital deficiency of the pericardium. Radiology, 77, 984.

Hering, A. C., Wilson, J. S., and Ball, R. E., Jr. (1960). Congenital deficiency of the pericardium. J. thorac. cardiovasc. Surg., $40,49$.

Kavanagh-Gray, D., Musgrove, E., and Stanwood, D. (1961). Congenital pericardial defects. Report of a case. New Engl. J. Med., 265, 692 .

Kovář, J., and Steinhart, L. (1959). Případ defektu osrdečníku predstìrajici nádor mezihrudí. (A case of defect of pericardium imitating a tumour of mediastinum.) Rozhl. Tuberk., 19, 44 (Czech).

Ladd, W. E. (1936). Congenital absence of the pericardium. New Engl. J. Med., 214, 183.

Moore, T. C., and Shumacker, H. B., Jr. (1953). Congenital and experimentally produced pericardial defects. Angiology, 4, 1.

Otto, A. W. (1831). A Compendium of Human and Comparative Pathological Anatomy, trans. J. F. South, section 19, \$162, p. 253. Fellows, I ondon.

Perna, G. (1909). Sopra un arresto di sviluppo della sierosa pericardica nell 'uomo. Anat. Anz., 35, 323.

Ronka, E. K. F., and Tessmer, C. F. (1944). Congenital absence of the pericardium. Report of a case. Amer. J. Path. 20, 137.

Rusby, N. L., and Sellors, T. H. (1945). Congenital deficiency of the pericardium associated with a bronchogenic cyst. Brit. J. Surg.,
32,357 .

Southworth, H., and Stevenson, C. S. (1938). Congenital defects of the pericardium. Arch. intern. Med., 61, 223.

Sunderland, S., and Wright-Smith, R. J. (1944). Congenital pericardial defects. Brit. Heart J., 6, 167.

Warner, C. L., Britt, R. L., and Ri'ey, H. D., Jr. (1958). Bronchopulmonary sequestration in infancy and childhood. J. Pediat., $53,521$.

Wilkinson, A. H., Jr., Buttram, T. L., Reid, W. A., and Howard, J. M. (1958). Cardiac injuries. Ann. Surg., 147, 347. 